\title{
Determinants of First Line Anti-Retroviral Treatment Failure Among Adult Human Immunodeficiency Virus Infected Patients in Western Oromia Public Hospitals, West Ethiopia
}

\author{
Fraol Jaleta $^{1, ~ *, ~ A l e m a y e h u ~ G e t a h u n ~}{ }^{2}$, Getu Bayissa $^{3}$ \\ ${ }^{1}$ Oromia Regional Health Bureau, Adama Public Health Research and Referral Laboratory Center, Adama, Ethiopia \\ ${ }^{2}$ Department of Public Health, College of Medical and Health Science, Wollega University, Nekemte, Ethiopia \\ ${ }^{3}$ Department of Pharmacy, College of Medical and Health Science, Wollega University, Nekemte, Ethiopia \\ Email address: \\ firanoljako1387@gmail.com (F. Jaleta), alemayehugthn@gmail.com (A. Getahun), alemayehug@wollegauniversity.edu.et (A. Getahun), \\ kiyabayisa@gmail.com (G. Bayissa) \\ ${ }^{*}$ Corresponding author
}

\section{To cite this article:}

Fraol Jaleta, Alemayehu Getahun, Getu Bayissa. Determinants of First Line Anti-Retroviral Treatment Failure Among Adult Human Immunodefficiency Virus Infected Patients in Western Oromia Public Hospitals, West Ethiopia. American Journal of Health Research. Vol. 7, No. 5, 2019, pp. 71-78. doi: 10.11648/j.ajhr.20190705.13

Received: July 1, 2019; Accepted: August 7, 2019; Published: September 2, 2019

\begin{abstract}
Back ground: First line antiretroviral treatment failure has led to increased HIV associated mortality especially in resource limited setting. A determinant of First line antiretroviral treatment failure is not well studied in Ethiopia. The objective of the study was to identify determinants of first line treatment failure among adults living with HIV in western Oromia public hospitals, West Ethiopia. Method: Unmatched case control study was conducted at public hospitals of West Oromia using medical record review. Cases were adult HIV patients on ART in selected hospitals who were switched to second line ART regimen because of first line treatment failure in the past ten years (2005-2015) and Controls were adult HIV patients on ART in selected hospitals who were on first line ART for greater or equal to six month in the same years (2005-2015).Data was collected by trained nurses (counselors) using checklists developed from Ministry of Health ART follow up form and entered to EPi data version 3.1 and transferred to SPSS version 20.0 for analysis. To identify determinants of first line anti-retroviral treatment failure, multivariate analysis with P-value $<0.05$ was done. Results: A total of 115 cases and 345 controls were included in the study. Baseline CD4 measure (AOR $[95 \% \mathrm{CI}]=3.96[1.84,8.54])$, regimen change due to drug stock out (AOR $[95 \% \mathrm{CI}]=2.54[1.38,4.66])$, treatment interruption $(\mathrm{AOR}[95 \% \mathrm{CI}]=5.09[2.39,10.82])$, adverse effect of drug (AOR $[95 \%$ $\mathrm{CI}]=8.49[1.87,38.42])$ and History of opportunistic infection $(\mathrm{AOR}[95 \% \mathrm{CI}]=2.15[1.28,3.64]$ were independently associated with first line antiretroviral treatment failure. Conclusion: Intervention for First line antiretroviral treatment failure needs to emphasize on regimen change due to drug stock out, treatment interruption, history of opportunistic infection, adverse effect of drug and base line CD4 $<50 \mathrm{cell} / \mu$.
\end{abstract}

Keywords: Treatment Failure, Antiretroviral Therapy, Case Control

\section{Introduction}

Human immunodeficiency Virus (HIV) is a virus which causes Acquired Immunodeficiency syndrome (AIDS) by which a failure of human immune system leads life threatening opportunistic infection. Introduction of Highly Active Anti-Retroviral Therapy (HAART) has led to an increase in survival among HIV-infected patients [1,2].
At the start of ART, first line regimen of two Nucleotides reverse transcriptase inhibitors backbone with one of nonnucleotide reverse transcriptase inhibitors is used. In case of first line treatment failure (anti HIV medication can't control the infection) there is a decision to start second line regimens which contain additional protease inhibitors. Treatment failure might happen in the form of virological failure, immunological failure and clinical progression. World Health Organization (WHO) defines treatment failure virologically 
as viral load persistently (at least 2 results) above 1000 copies $/ \mathrm{ml}$. The success of antiretroviral treatment is defined more specifically by viral suppression [3-5].

Clinical failure is the combination of New or recurrent opportunistic infection (OI), malignancy, pulmonary Tuberculosis (TB) and severe bacterial infections whereas immunological failure includes fall of CD4 count to pretherapy baseline or CD4 levels rise from the baseline after six months of treatment [6].

According to WHO report, about 36.9 million people were living with HIV /AIDS worldwide and around 1.2 million died at the end of 2014 and an estimated 2 million people were newly infected individuals [7, 8]. During 2014, SubSaharan Africa accounted more than two third of global AIDS related death which was felt by $48 \%$ of death in 2004 due to accesses of Anti-Retroviral Therapy. To the contrary, treatment failure has been shown to increase morbidity and mortality $[9,10]$.

The same report implies, about $6 \%$ of patients receiving first-line therapy in sub-Saharan Africa need to switch to second-line regimens in any given year due to first line ART failure $[11,12]$. Ethiopia is one of the Sub-Saharan African countries most severely affected by HIV/AIDS. It has the fifth largest population of HIV infected individuals living in Africa, which accounts to approximately $4 \%$ of the world's HIV/AIDS cases. According to federal Ministry of Health (FMOH) report, there were 1.2 million people living with HIV, and 397,818 are estimated to be in need of antiretroviral treatment in 2011. Adult Prevalence was decreased from 1.5 in 2013 to $1.1 \%$ in 2015 . But the number of patients on second line due to treatment failure and others remain low which is $1.7 \%$ of all of ART recipients $[13,14]$.

Patients with first line treatment failure due to inadequate drug adherence are at high risk of a subsequent treatment failure on second-line ART $[4,15]$ Factors that lead to ART treatment failure are not well studied in Ethiopia. Therefore, the aim of this study was to determine risk factors associated with first line antiretroviral treatment failure which was defined in this study as regimen changed to second line due to clinical failure with WHO stage III and IV and immunological failure considered as fall of CD4 count to pre-therapy baseline after six months on treatment. The study was also aimed to identify patient and health service related factor contributed for treatment failure. Particularly, this finding is an input for zonal and woreda health offices, partners and health care providers to design better strategies that ensure the effectiveness of HAART which minimizes the risk of drug resistance or increases the suppression of viral load. It also supports the patients to be aware of their drug intake as per scheduled.

\section{Methods}

\subsection{Study Area and Period}

Unmatched case control study was conducted from
January 20 to February 2, 2017 in four public hospitals (Nekemte, Ghimbi, Nedjo and Dembidolo) located in west Oromia which were selected purposively based on ART service initiation before ten years preceding the study. There were 4830 enrolled adult HIV/AIDS patients in the selected hospitals [16-19].

\subsection{Study Population}

The study population consisted of cases and controls. Cases were adult HIV patients on ART in Public hospitals who failed first line ART and switched to second line ART regimen in the past ten years (2005-2015) and Controls were adult HIV patients on ART in selected hospitals who were on first line ART for equal or greater than six months and had not failed first line treatment in the same years (2005-2015).

Patients with incomplete information and transfer in (TI) were not included in the study.

\subsection{Sample Size and Sampling Procedure}

Sample size was calculated using EPI Info version 7.1 .4 by considering exposure to neverapin based first line regimen as the main exposure. From the literature it is $41 \%$ and $27 \%$ in cases and controls respectively [20]. Power 80\%, 95\% CI, case to control ratio $1: 3$ (case to control) and a total of 460 were included in the study.

Sampling frame for case and control was prepared using unique identification number from medical records. Cases and controls were selected randomly and proportional to the size of the study population who started ART in the past ten years (January 2005- January 2015) from four selected public hospitals. Finally, 115 of the patients who were on second line drug regimen were selected as a case and 345 of those on first line drug regimen were selected as control.

\subsection{Data Collection Methods and Tools}

Data was collected from medical records using checklists developed from FMOH of Ethiopia ART follow up form and guideline. Patient related variables which includes levels adherence measured before cases switched to second line drug, history of treatment interruption before treatment failure, baseline CD4 count, WHO clinical stage, Duration on first line ART before failure, History of diarrhea, health service and drug related variables which includes distance from health facility type of initial first line regimen, regimen change due to drug stock out, history of adverse effect before switched to second line treatment and socio-demographic factors were extracted from medical record review. Eight ART nurses (counselors) were recruited from study hospitals and two days training was provided for data collectors which include practical tests to ensure their competency of filling checklist. There was a close supervision and daily based checkup for completeness of filled questionnaire during data collection.

\subsection{Data Processing and Analysis}

Data was first checked manually for completeness and 
then entered into Epidata version 3.1. After data entry and cleaning, the data was transferred to SPSS version 20.0 for analysis. Bivariate analysis was performed using binary logistic regression. Variables which showed significant association in the bivariate analyses $(\mathrm{P}<0.2)$ were candidates for the multivariate logistic regression model. To control the effect of confounding variables, multivariate logistic regressions were done. Explanatory variables significantly associated with outcome variable with $\mathrm{p}$-value $<0.05$ in multivariate logistic regression were determined as independent predictors of first line treatment failure. Finally, conclusion and recommendation were made based on the findings. Adjusted OR and 95\% CI were used to interpret the findings.

The study was ethically approved by Ethical Review Committee of Wollega University. Formal letter from Wollega university department of public health was written and submitted to selected public hospitals and permission was obtained from each hospital. Identification of participant was done only through ART identification codes and name of the participant was not included in the checklist in order to ensure the confidentiality of the patient information.

\section{Results}

\section{Socio-demographic Characteristics}

A total of 460 (115 cases and 345 controls) HIV patients were included in the study. The mean age at which participants started ART was $33(\mathrm{SD} \pm 9)$ and $34(\mathrm{SD} \pm 9)$ years for the case and control respectively. 59 (51.3\%) of cases and $207(60.0 \%)$ of controls were females. Regarding to religion, $60(52.2 \%)$ of cases and $145(42 \%)$ of controls were protestant [Table 1].

The study also tried to assess adherence and depicted out $91(79.0 \%)$ of cases and $331(95.9 \%)$ of controls had good adherence to the drug. Concerning to Substance use only 17 (14.8\%) of cases and 38 (19.4\%) of controls used substance. The media duration on first line ART for case and controls were 72 and 53 months respectively.
Clinical diseases and other health related problems related variables. During initiation of HAART, 74 (64.3\%) of case and $150(43.5 \%)$ of controls were on WHO clinical stage III. Functional status of patients before ART initiation was assessed and $69(60 \%)$ of cases and $287(83.2 \%)$ of controls were at working status and the rest were ambulatory. 60 $(52.2 \%)$ of cases and $88(25.5 \%)$ of controls had history of opportunistic infection [Table 2].

Health service and drug related variables of study population

According to the result, $4(55.7 \%)$ of cases and 201 $(58.1 \%)$ of controls resides in $<10 \mathrm{~km}$ from ART clinics. Initially, $49(42.6 \%)$ of cases and $78(22.6 \%)$ of controls were on initial regimen of $\mathrm{d} 4 \mathrm{~T}+3 \mathrm{TC}+\mathrm{NVP}$. Adverse effect of drug used for ART was37 (32.2\%) for cases and $27(7.8 \%)$ for controls. Regimen was changed for 50 $(43.5 \%)$ of cases and64 (18.6\%) of controls due to drug stock out [Table 3].

Determinants of first line anti-retroviral treatment failure

In multivariate logistic regression six variables were independently associated with first line anti-retroviral treatment failure. HIV/AIDS patients with Baseline CD4 <50 cell/microliter were around four times more likely to fail first line antiretroviral treatment when compared with those patients base line CD4 $>150$ cell/microliter (AOR [95\% CI] $=3.96[1.84,8.54])$. Patients with regimen change due to drug stock out were more likely to develop first line treatment failure when compared with those whose regimen was not changed (AOR [95\% CI] $=2.54[1.38,4.66]$ ). Study participants with history of Adverse effect were around five times more likely to fail first line treatment than who had no $(\mathrm{AOR}[95 \% \mathrm{CI}]=5.33[2.78,10.24])$. History of opportunistic infection had more likely to fail first line antiretroviral treatment compared with no opportunistic infection $(\mathrm{AOR}[95 \% \mathrm{CI}]=2.15[1.28,3.64])$. Patients interrupted treatment during ART Treatment were five times more likely to fail first line treatment when compared with not interrupted treatment $(\mathrm{AOR}[95 \% \mathrm{CI}]=5.09[2.39,10.82])$ [Table 4].

Table 1. Socio-Demographic characteristics of adult HIV infected patients in public hospitals of Western Oromia, West Ethiopia, 2017.

\begin{tabular}{llll}
\hline \multirow{2}{*}{ Variables } & & Patient category & Controls (n=345) \\
\cline { 3 - 4 } SEX & & Cases $(\mathbf{n}=\mathbf{1 1 5})$ & $138(40 \%)$ \\
& Male & $56(48.7)$ & $207(60 \%)$ \\
\multirow{2}{*}{ AGE } & Female & $59(51.3 \%)$ & $28(8.1 \%)$ \\
& & & $179(51.9 \%)$ \\
& $15-24$ years & $15(13.1 \%)$ & $108(31.3 \%)$ \\
& $25-34$ years & $48(41.7 \%)$ & $30(8.7 \%)$ \\
\multirow{2}{*}{ Religion } & $35-44$ years & $42(36.5 \%)$ & $145(42 \%)$ \\
& $45^{+}$years & $10(8.7 \%)$ & $159(46.1 \%)$ \\
& & & $37(10.7 \%)$ \\
& Protestant & $60(52 \%)$ & $4(1.2 \%)$ \\
& Orthodox & $42(36.5 \%)$ & \\
\hline
\end{tabular}




\begin{tabular}{llll}
\hline \multirow{2}{*}{ Variables } & & Patient category & Controls (n=345) \\
\cline { 3 - 4 } & Single & Cases $(\mathbf{n}=\mathbf{1 1 5})$ & $49(14.2 \%)$ \\
& Married & $24(24 \%)$ & $225(65.2 \%)$ \\
Divorced & $66(57.4 \%)$ & $19(5.5 \%)$ \\
& Widowed & $4(3.5 \%)$ & $31(9 \%)$ \\
& Separated & $13(11.5 \%)$ & $21(6.1 \%)$ \\
Educational status & & $8(7.1 \%)$ & $91(26.4 \%)$ \\
& None & $28(24.3 \%)$ & $129(37.4 \%)$ \\
& Primary & $44(38.3 \%)$ & $95(27 \%)$ \\
& Secondary & $32(27.8 \%)$ & $30(8.7 \%)$ \\
Tertiary & $11(9.6 \%)$ & $270(78.3 \%)$ \\
Occupational status & & $71(20.6 \%)$ \\
& Non-employed & $92(80 \%)$ & $4(1.2 \%)$ \\
\hline
\end{tabular}

*Other: Adventist, Catholic and Jehovah

Table 2. Patient and clinical diseases related variables of adult HIV infected patients in public hospitals of western Oromia, West Ethiopia, 2107.

\begin{tabular}{|c|c|c|c|}
\hline \multirow{2}{*}{ Variables } & & \multicolumn{2}{|c|}{ Patient category } \\
\hline & & Cases & Controls \\
\hline \multicolumn{4}{|l|}{ Adherence } \\
\hline & Good adhered & $91(79.1 \%)$ & $331(95.9 \%)$ \\
\hline & Fairly adhered & $18(15.7 \%)$ & $8(2.3 \%)$ \\
\hline & Poorly adhered & $6(5.2 \%)$ & $6(1.7 \%)$ \\
\hline \multicolumn{4}{|c|}{ Treatment interruption } \\
\hline & Yes & $24(20.9 \%)$ & $19(5.5 \%)$ \\
\hline & No & $91(79.1 \%)$ & $326(94.5 \%)$ \\
\hline \multicolumn{4}{|c|}{ Substance use } \\
\hline & Yes & $17(14.8 \%)$ & $67(19.4 \%)$ \\
\hline & No & $98(85.2 \%)$ & $278(80.6 \%)$ \\
\hline \multicolumn{4}{|c|}{ Type of substance } \\
\hline & Alcohol & $16(94.1 \%)$ & $48(71.6 \%)$ \\
\hline & Tobacco & $1(5.9 \%)$ & $13(19.4 \%)$ \\
\hline & Khat & $0(0 \%)$ & $4(5.9 \%)$ \\
\hline & Soft or hard drug & $0(0 \%)$ & $2(2.9 \%)$ \\
\hline \multicolumn{4}{|c|}{ Duration on first line ART } \\
\hline & $<24$ month & $98(85.2 \%)$ & $278(80.6 \%)$ \\
\hline & $>24$ month & $7(6.1 \%)$ & $52(15.1 \%)$ \\
\hline \multicolumn{4}{|c|}{ WHO stages } \\
\hline & WHO stage One & $12(10.4 \%)$ & $93(27 \%)$ \\
\hline & WHO stage Two & $22(19.1 \%)$ & $95(27 \%)$ \\
\hline & WHO stage Three & $74(64.3 \%)$ & $150(43.5 \%)$ \\
\hline & WHO stage Four & $7(6.1 \% 0$ & $7(2 \%)$ \\
\hline \multicolumn{4}{|c|}{ Chronic diarrhoea } \\
\hline & Yes & $32(27.8 \%)$ & $98(28.4)$ \\
\hline & No & $83(72.2 \%)$ & $247(71.6 \%)$ \\
\hline \multicolumn{4}{|c|}{ History of GI problem } \\
\hline & Yes & $53(46.1 \%)$ & $103(29.9 \%)$ \\
\hline & No & $62(53.9)$ & $242(70.1 \%)$ \\
\hline \multicolumn{4}{|c|}{ Opportunistic Infection } \\
\hline & Yes & $60(52.2 \%)$ & $88(25.5 \%)$ \\
\hline & No & $55(47.8 \%)$ & $261(74.7 \%)$ \\
\hline \multicolumn{4}{|c|}{ Type of opportunistic infection } \\
\hline & Pneumocysticcarini pneumonia & $4(3.5 \%)$ & $6(1.7 \%)$ \\
\hline & Bacterial pneumonia & $16(13.9 \%)$ & $35(10.1 \%)$ \\
\hline & CNS Toxoplasmosis & $1(.9 \%)$ & $1(0.3 \%)$ \\
\hline & Pulmonary TB & $15(13 \%)$ & $18(5.2 \%)$ \\
\hline & Extra pulmonary TB & $4(3.5 \%)$ & $9(2.6 \%)$ \\
\hline & Other & $17(14.8 \%)$ & $15(4.3 \%)$ \\
\hline
\end{tabular}

Abbreviation: CNS, central nerves system; TB, tuberculoses; GI, gastro intestinal; WHO, world health organization. 
Table 3. Health service and drug related variables of adult HIV infected patients in selected hospitals of western Oromia, west Ethiopia, 2017.

\begin{tabular}{|c|c|c|}
\hline \multirow{2}{*}{ Variables } & \multicolumn{2}{|c|}{ Patient Category } \\
\hline & Case (\%) & Controls (\%) \\
\hline \multicolumn{3}{|l|}{ Distance in $\mathrm{km}$} \\
\hline$<10 \mathrm{~km}$ & $64(55.7 \%)$ & $201(58.1 \%)$ \\
\hline$>10 \mathrm{~km}$ & $51(44.3 \%)$ & $144(41.7 \%)$ \\
\hline \multicolumn{3}{|l|}{ Initial first line regimen } \\
\hline $\mathrm{D} 4 \mathrm{~T}+3 \mathrm{TC}+\mathrm{NVP}$ & $49(42.6 \%)$ & $78(22.6 \%)$ \\
\hline $\mathrm{D} 4 \mathrm{~T}+3 \mathrm{TC}+\mathrm{EFV}$ & $12(10.4 \%)$ & $30(8.7 \%)$ \\
\hline $\mathrm{ZDV}+3 \mathrm{TC}+\mathrm{NVP}$ & $13(11.3 \%)$ & $48(13.9 \%)$ \\
\hline $\mathrm{ZDV}+3 \mathrm{TC}+\mathrm{EFV}$ & $9(7.8 \%)$ & $19(5.5 \%)$ \\
\hline $\mathrm{TDF}+3 \mathrm{TC}+\mathrm{EFV}$ & $25(21.7 \%)$ & $148(42.9 \%)$ \\
\hline $\mathrm{TDF}+3 \mathrm{TC}+\mathrm{NVP}$ & $7(6.1 \%)$ & $22(6.4 \%)$ \\
\hline \multicolumn{3}{|l|}{ EFV based } \\
\hline Yes & $48(41.7 \%)$ & $200(58 \%)$ \\
\hline No & $67(58.3 \%)$ & $145(42 \%)$ \\
\hline \multicolumn{3}{|l|}{ NVP based } \\
\hline Yes & $67(58.3 \%)$ & $146(42.3 \%)$ \\
\hline No & $48(41.7 \%)$ & $199(57.7 \%)$ \\
\hline \multicolumn{3}{|l|}{ Adverse effect } \\
\hline Yes & $37(32.2 \%)$ & $27(7.8 \%)$ \\
\hline No & $78(67.8 \%)$ & $318(92.2 \%)$ \\
\hline \multicolumn{3}{|l|}{ Co-medication } \\
\hline Yes & $38(33 \%)$ & $94(27.2 \%)$ \\
\hline No & $77(67 \%)$ & $251(72.8 \%)$ \\
\hline \multicolumn{3}{|l|}{ Regimen change due to drug stock out } \\
\hline Yes & $50(43.5 \%)$ & $64(18.6 \%)$ \\
\hline No & $65(56.5 \%)$ & $281(81.4 \%)$ \\
\hline
\end{tabular}

Abbreviations: KM, kilormete; D4T, stavudine; 3TC, lamivudine; NVP, Niverapine, EFV, efanfrenze;TDF, tenofovir.

Table 4. Multivariate analysis associated with first line anti-retroviral treatment failure among adult HIV infected patients in selected hospitals of western Oromia, west Ethiopia, 2017.

\begin{tabular}{|c|c|c|c|c|c|}
\hline \multirow{2}{*}{ Variables } & \multicolumn{2}{|c|}{ Patient Category } & \multirow{2}{*}{ COR (95\% CI) } & \multirow{2}{*}{$\operatorname{AOR}(95 \% \mathrm{CI})$} & \multirow{2}{*}{ P-value } \\
\hline & Case & Controls & & & \\
\hline \multicolumn{6}{|l|}{ Baseline CD4 } \\
\hline$<50$ cell $/$ microlitre & $21(18.3 \%)$ & $35(10.1 \%)$ & $13.56(6.87-26.74)$ & $3.96(1.84-8.54)$ & 0.000 \\
\hline $50-150$ cell $/$ microlitre & $46(40 \%)$ & $97(30.8 \%)$ & $3.73(1.88-7.41)$ & $14.84(6.86-32.08)$ & 0.000 \\
\hline$>150 \mathrm{cell} / \mathrm{microlitre}$ & $48(41.7 \%)$ & $248(78.7 \%)$ & 1.00 & 1.00 & \\
\hline \multicolumn{6}{|c|}{ Regimen change due to drug stock out } \\
\hline No & $65(56.5 \%)$ & $281(81.4 \%)$ & 1.00 & 1.00 & \\
\hline \multicolumn{6}{|l|}{ Adverse effect } \\
\hline Yes & $37(32.2 \%)$ & $27(7.8 \%)$ & $5.59(3.20-9.73)$ & $5.33(2.78-10.24)$ & 0.000 \\
\hline No & $78(67.8 \%)$ & $318(92.2 \%)$ & 1.00 & 1.00 & \\
\hline \multicolumn{6}{|l|}{ Treatment interruption } \\
\hline Yes & $24(20.9 \%)$ & $19(5.5 \%)$ & $4.53(2.37-8.63)$ & $5.09(2.39-10.82)$ & 0.002 \\
\hline \multicolumn{6}{|l|}{ History of opportunistic OI } \\
\hline Yes & $57(49.6 \%)$ & $84(24.3 \%)$ & $3.19(2.06-4.94)$ & $2.15(1.28-3.64)$ & 0.004 \\
\hline No & $58(50.4 \%)$ & $261(75.7 \%)$ & 1.00 & 1.00 & \\
\hline
\end{tabular}

Abbreviations: CD4, cluster differentiation; OI, opportunistic infection; COR, crude odd ratio; AOR, adjusted odd ratio; CI, confidence interval.

\section{Discussion}

Treatment failure is one of the burning issues in clinical management of HIV patients follow up on ART now days. In this study, it was assessed based on clinical failure which was described by WHO clinical stages (III and IV) and immunological failure considering the decrease of $\mathrm{CD} 4$ count to pre-therapy baseline or CD4 level that has not been raised from baseline count after six month start of ART. Long stay on a fail of first line treatment increases the risk of mortality and morbidity inciting treatment failure and development of drug resistance. In this study, several risk factors associated with treatment failure described by clinical and immunological failure were identified. From baseline laboratory Measures, this study identified that patients with baseline CD4 $<50$ cell/microliter 
have 3.96 times more risk of a developing treatment failure than those with higher CD4 count. This study is also similar with the study conducted in Kenya that depicted patients with CD4 count below $50 \mathrm{cel} / \mu \mathrm{l}$ increases the probability of treatment failure more than 5 folds. This study is also consistent with the study done in Addis Ababa in which patients with base line CD4 less than 50 cell/ $\mu$ l failed 2.7 times than that of higher CD4 counts. This might be due to patient with low base line CD4 count have lesser immunity that can result in the risk of developing immunological failure and consequently become high risk for treatment failure $[21,22]$. Patents whose regimen was changed due to drug stock out were failed 2.5 times more than that of whose regimen has not been changed due to drug stock out. This study is consistent with the study conducted in Zshivane district of Zimbabwe in which patients who faced drug stock out were 3.02 times more to have first line treatment failure than that of who have not faced. This might be due to the variability of potency and dosing of replaced drugs and the initial drug in first line ARV options. Frequent change of drug due to stock out might also increases the chance of acquiring adverse affect of drug and drug resistance.

However, this study is not supported with the study done in Harare central hospital of Zimbabwe in which regimen change was not associated significantly with first line treatment failure. The discrepancy might be treatment change in Harare central hospital of Zimbabwe was assessed due to some other factors unlike in this study which specifically focused on drug stock out. The other reason might be due to the difference in the study design and the sampling technique $[23,24]$.

The finding of this study indicates that adverse effect of the drug is another independent predictor of treatment failure. Patients who developed adverse effect were 5.33 times more likely in developing treatment failure than those who has not developed adverse effects. This study is supported with the study done in Harare Central hospital adult opportunistic clinics of Zimbabwe that showed patients with Severe depression due to side effect of ART drug was 3.7 times more likely at risk of developing first line antiretroviral treatment failure than that of without depression. The possible reason might be adverse effects which are probably caused by improper selection of drug or co morbidity conditions lead to regimen change and discontinuation which consequently increase the risk of treatment failure. However, this study is inconsistent with the study done in Zshivane district of Zimbabwe in which there was no association of drug side effect with first line antireviral treatment failure. The possible reason for the variation may be due to the difference in the method of data collection in which interview was conducted by semi structured questionnaire and checklist for medical record review in Zimbabwe. When conducting interview with patient there may be information or recall bias [23, 24]

Unplanned treatment interruption was strongly associated with first line anti retroviral treatment failure in this study. Patients who interrupted treatment were 5.08 times at risk of treatment failure when compared to patients who had not experienced treatment interruption. This study is supported by the study done in public and private hospitals of Addis Ababa in which the odd of first line treatment failure among case was 5.36 times when compared to controls. This study is also comparable with the study done in Zimbabwe in which patient with discontinuation of treatment are 4.4 more likely failed first line treatments than those who haven't experienced discontinuation of treatment. Unplanned treatment interruption may lead to damage of immune system, an increase in the risk of opportunistic infection and development of drug resistance which may leads to the risk of treatment failure. However, this study is inconsistent with the study conducted in university of Gondar hospital North West Ethiopia, in which history of treatment interruption is not independently associated with first line treatment failure. The possible reason for discrepancy may be, the study conducted in Gondar was only in single health facility with low sample size which may affect the precision of the study and qualities of ART patients management might be differ from this study which included four health facilities [21, 23, 24].

History of opportunistic infection before failure of first line treatment was another independent risk factor for treatment failure. Patients with history of opportunistic infection failed 2.15 times more than those who had not developed opportunistic infection. This finding is consistent with the study done in hospitals of Bale zone in which the odd of treatment failure among case increased more than 5 folds. This might be due to initiation of antiretroviral therapy before treating opportunistic infection which decreases the effectiveness of immunological function decreasing CD4 count and proliferation of opportunistic infections. This might causes immunological failure which incites the risk of developing first line antiretroviral treatment failure and immune suppression in HIV infected patients. However, the study was not comparable with the study done in Uganda, Kampala which indicates that there was no association of opportunistic infection with treatment failure. This finding is not in line with the study conducted in university of Gondar teaching hospital [25-27].

\section{Limitation of the Study}

Viral load test which is one of the decision criteria for ART failure was not included in the study due to the absence of the test service in the study area

\section{Conclusion}

According to this study the determinants of first line ART treatment failure were: Baseline CD4, Regimen change due to drug stock out, treatment interruption, adverse effect and history of opportunistic infection. Health professionals should regularly follow the patients to avoid unplanned treatment interruption and they should also aware of patients with lower CD4 count for early initiation of ART. If there is an acute opportunistic infection, it should be addressed first since it suppresses patient immunity being life threatening if 
left untreated. Health facilities should monitor supply management system by regular performance of inventory management to minimize regimen change due to drug stock out. Oromia Regional Health Bureau must support the health facilities to implement viral load test service which is the gold standard for decision of virological failure.

\section{List of Abbreviations and Acronyms}

$\begin{array}{ll}\text { AIDS } & \text { Acquired Immune Deficiency Syndrome } \\ \text { AOR } & \text { Adjusted Odds Ratio } \\ \text { ART } & \text { Anti-Retroviral Therapy } \\ \text { CD4 } & \text { Cluster Differentiation } \\ \text { CI } & \text { Confidence Interval } \\ \text { FMOH } & \text { Federal Ministry of Health } \\ \text { HAART } & \text { HighlyActiveAnti-RetroviralTherapy } \\ \text { HIV } & \text { HumanImmunedeficiencyVirus } \\ \text { OI } & \text { Opportunistic Infection } \\ \text { OR } & \text { Odds Ratio } \\ \text { SD } & \text { Standard Deviation } \\ \text { SPSS } & \text { Statistical Package for the Social Sciences } \\ \text { TB } & \text { Tuberculosis } \\ \text { TI } & \text { Transfer In } \\ \text { WHO } & \text { World Health Organization }\end{array}$

\section{Declarations}

\section{Ethics Approval and Consent to Participate}

Ethical clearance was obtained from Wollega University ethical review committee. Formal letter from Wollega university department of public health was written and submitted to the four selected Hospitals. Name of the participant was not included. Permission was assured from respected hospitals. No consent since based on secondary data.

\section{Consent for Publication}

Not applicable

\section{Availability of Data and Materials}

The datasets generated and/or analyzed during the current study are not publicly available due to confidentiality and ethics for HIV/AIDS patients, But available from the corresponding author on reasonable request.

\section{Competing Interests}

The authors declare that they have no competing interests

\section{Funding}

Nekemte Public Health Research and Referral Laboratory center contributed financial support for data collection.

\section{Authors' Contributions}

FJ conceived the study, involved in the data analysis and Report writing and drafted the manuscript. AG was involved in the conception, design, data analysis and review. GB was involved in conception, design and data analysis. All authors read and approved the manuscript.

\section{Acknowledgements}

We would like to thank Wollega University and Nekemte public health research and referral laboratory center for their financial and material support. We also appreciate and extend our special thank to the selected hospitals for their cooperation in providing essential information. Lastly, we, acknowledge health care providers at ART clinics of Nekemte, Ghimbi, Nadjo and DembiDolo hospitals who were involved in data collection.

\section{References}

[1] Heymann D. Control of Communicable Diseases Manuel. 19th ed. American Public Health Association; 19 edition (October 25, 2008); 2008. 3 p.

[2] Aldous JL, Haubrich RH. Defining treatment failure in resource-rich settings. Curr Opin HIV AIDS [Internet]. 2009; 4 (6): 459-66. Available from: http://www.pubmedcentral.nih.gov/articlerender.fcgi?artid=29 46177\& tool=pmcentrez\&rendertype $=$ abstract

[3] Seshaiah K V, Rao DS, Rao KS, Anuradha M, Venkatesh P, Kranthi Kumar P. Prevalence of Failure of First-Line AntiRetroviral Therapy in HIV Patients: A Retrospective CrossSectional Study of Six Districts of Andhra Pradesh Over One Decade. Sch J Appl Med Sci Sch J App Med Sci [Internet]. 2015; 3 (2C): 705-9. Available from: www.saspublisher.com

[4] Ethiopia Federal HIV/AIDS Prevention and Control Office. Guidelines for Management of Opportunistic Infections and Anti-Retroviral Treatment in Adolescents and Adults in Ethiiopia, March 2008. 2008; (March): 1-109.

[5] Ministry of Health and Family welare of India NACO. Antiretroviral Therapy Guidelines for HIV-Infected Adults and Adolescents: May 2013. 2013; 40-5.

[6] Liberia Ministry of Health and Social Welfare. Integrated Guidelines for Prevention, Testing, Care and Treatment of HIV/AIDS in Liberia 2nd Edition. 2007; (December): 1-238.

[7] World Health Organization (WHO). Global update on the health sector response to HIV, 2014. Vol. 6. 2014.

[8] The HJ Kaiser Family foundation. The Global HIV / AIDS Epidemic. 2017; (November): 6-9.

[9] UNAIDS. Global Aids Response Progress Reporting 2015 [Internet]. Vol. 371, The Lancet. 2015. 218 p. Available from: www.unaids.org//unaids//2013/gr2013/UNAIDS_Global_Rep ort_2013\%5Cnhttp://ovidsp.ovid.com/ovidweb.cgi?T=JS\&PA $\mathrm{GE}=$ reference $\& \mathrm{D}=$ emed $8 \& \mathrm{NEWS}=\mathrm{N} \& \mathrm{AN}=2008031311 \% 5 \mathrm{C}$ nhttp://www.biomedcentral.com/1471-2431/14/280

[10] Fätkenheuer G, Theisen A, Rockstroh J, Grabow T, Wicke C, Becker $\mathrm{K}$, et al. Virological treatment failure of protease inhibitor therapy in an unselected cohort of HIV-infected patients. Aids [Internet]. 1997; 11 (14): F113-6. Available from: http://ovidsp.ovid.com/ovidweb.cgi?T=JS\&PAGE=reference $\& \mathrm{D}=$ emed4\&NEWS $=\mathrm{N} \& \mathrm{AN}=1997338954$ 
[11] Mocroft A, Ledergerber B, Viard JP, Staszewski S, Murphy M, Chiesi A, et al. Time to virological failure of 3 classes of antiretrovirals after initiation of highly active antiretroviral therapy: results from the EuroSIDA study group. J Infect Dis [Internet]. 2004; 190 (11): 1947-56. Available from: http://www.ncbi.nlm.nih.gov/pubmed/15529259

[12] UNAIDS. GLOBAL REPORT: UNAIDS report on the global AIDS epidemic 2013 [Internet]. Unaids. 2013. 198 p. Available

from: www.unaids.org//unaids//2013/gr2013/UNAIDS_Global_Rep ort_2013

[13] Ethiopian Public Health Institute and FMOH. HIV Related Estimates and Projections for Ethiopia- 2014. Addis Ababa; 2014.

[14] Wilhelmson S, Reepalu A, Balcha TT, Jarso G, Björkman P. Retention in care among HIV-positive patients initiating second-line antiretroviral therapy: A retrospective study from an Ethiopian public hospital clinic. Glob Health Action. 2016; 9 (1): $1-8$

[15] Arg M, Tietjen I, Gatonye T, Ngwenya BN, Namushe A, Simonambanga $\mathrm{S}$, et al. Guidelines for the Use of Antiretroviral Agents in HIV-1-Infected Adults and Adolescents Developed by the DHHS Panel on Antiretroviral Guidelines for Adults. J Ethnopharmacol [Internet]. 2016; 5 (January): 512-3. Available from: http://dx.doi.org/10.1016/S1473-3099(16)00013-

X\%5Cnhttp://dx.doi.org/10.1016/j.jep.2016.06.040

[16] Nekemte refferal Hospital. Nekemte refferal Hospital Annual report. Nekemte; 2015.

[17] Nedjo Hospital. Nedjo Hospital Annual report. Nedjo; 2015.

[18] Gimbi Hospital. Gimbi Hospital Annual report. Gimbi; 2015.

[19] Dembi Dollo Hospital. Dembidollo Hospital Annual report. Dembidollo; 2015.

[20] Datay MI, Boulle A, Mant D, Yudkin P. Associations with virologic treatment failure in adults on antiretroviral therapy in South Africa. J Acquir Immune Defic Syndr. 2010 Aug; 54 (5): 489-95.

[21] Yalemwork G, Sahilu A. Determinants of first line antiretroviral treatment failure in public hospitals of Addis
Ababa, Ethiopia: unmatched case control study. J Biol Agric Healthc [Internet]. 2014; 4 (15): 1-12. Available from: http://www.iiste.org/Journals/index.php/JBAH/article/view/14 $197 / 14505$

[22] Kwobah CM, Mwangi AW, Koech JK, Simiyu GN, Siika AM. Factors Associated with First-Line Antiretroviral Therapy Failure amongst HIV-Infected African Patients: A CaseControl Study. World J AIDS. 2012; 2 (July 2011): 271-8.

[23] Matare T, Gombe N, Shambira G, Tshimanga M, Bangure D, Mungati $\mathrm{M}$, et al. Factors Associated with Human Immunodeficiency Virus First Line Treatment Failure in Zvishavane District, Zimbabwe, 2014. Austin J HIV/AIDS Res Open. 2015; 2 (1): 1-6.

[24] Chawana TD, Reid A, Bwakura T, Gavi S, C F B Nhachi. Factors Influencing Treatment failure in HIV Positive Adult Patients on First Line Antiretroviral Therapy. Vol. 60, The Central African Journal of Medicine. 2014. p. 29-36.

[25] Ayalew MB, Kumilachew D, Belay A, Getu S, Teju D, Endale $\mathrm{D}$, et al. First-line antiretroviral treatment failure and associated factors in HIV patients at the University of Gondar Teaching Hospital, Gondar, Northwest Ethiopia. HIV AIDS (Auckl) [Internet]. 2016; 8: 141-6. Available from: http://www.ncbi.nlm.nih.gov/pubmed/27621669\%5Cnhttp://w ww.pubmedcentral.nih.gov/articlerender.fcgi?artid=PMC5015 875

[26] Sebunya R, Musiime V, Kitaka S, Ndeezi G. Incidence and risk factors for first line anti retroviral treatment failure among Ugandan children attending an urban HIV clinic. AIDS Res Ther [Internet]. 2013; 10 (1): 25. Available from: http://aidsrestherapy.biomedcentral.com/articles/10.1186/1742 $-6405-10-25$

[27] Haile D, Takele A, Gashaw K, Demelash H, Nigatu D. Predictors of treatment failure among adult antiretroviral treatment (ART) clients in Bale Zone Hospitals, South Eastern Ethiopia. PLoS One. 2016; 11 (10): 1-14.

[28] Ebonyi AO, Oguche S, Ejeliogu EU, Okpe SE, Agbaji OO, Sagay SA, et al. Risk Factors for First-line Antiretroviral Treatment Failure in HIV-1 Infected Children Attending Jos University Teaching Hospital, Jos, North Central Nigeria. 2014; 4 (15): 2983-94. 